\title{
Analysis of Covid-19 Hospital Admissions in Ivano-Frankivsk, Ukraine
}

\author{
Oryna Detsyk ${ }^{1}$ (D), Natalia Fedorkiv ${ }^{1}$ (D), Olha Burak ${ }^{1^{*}}$ (D), Roksolana Kaluzhna ${ }^{1}$
}

\begin{abstract}
The Covid-19 pandemic has a substantial impact on socioeconomic, political, demographic, and other aspects of life. Effective healthcare is, however, a primary determinant of successful fighting against Covid-19. The analysis of local healthcare indicators serves as a source for estimating pandemic magnitude and the adaptation of healthcare at a national level. In this study, the rates of Covid-19 hospital admissions to the Ivano-Frankivsk City Hospital, Ukraine, from April 2020 to May 2021 were analysed. All cases were grouped by age, sex, and the type of admission; data were analyzed monthly and seasonally. The peaks of hospital admissions were observed in November 2020 and March 2021; however, the highest mortality rates were seen from August to November 2020. The analysis of age- and sex-disaggregated Covid-19 mortality data showed the predominance of elderly males $(61.9 \%, 66.6 \pm 3.9$ years) over females $(38.1 \%, 71.8 \pm 2.3$ years). The ratio of hospital admissions was unstable: the percentage of emergency, GP-referred and self-referred admissions was similar from April to May 2020; however, GP-referred admissions prevailed, and the number of self-referral patients decreased twice between March and May 2021. In conclusions, the trends in hospital admissions were similar to those reported in other studies. However, the differences in time frames and socio-demographic characteristics were observed that highlights the importance of considering regional, social and geographic aspects of the population when improving the capacity of healthcare system and establishing effective preventive measures against the pandemic at the local level.

Keywords

Covid-19; Case Fatality Rate; Hospital Admission; Health Care

${ }^{1}$ Department of Social Medicine and Public Health, Ivano-Frankivsk National Medical University, Ivano-Frankivsk, Ukraine

*Corresponding author: oburak@ifnmu.edu.ua

Copyright @Oryna Detsyk, Natalia Fedorkiv, Olha Burak, Roksolana Kaluzhna, 2021
\end{abstract}

\section{Introduction}

The coronavirus Covid-19 pandemic is a global health crisis and the greatest challenge the world has faced in our lifetime $[1,2]$. It has dramatically changed our lives. Since its emergence in Asia at the end of 2019 [3, 4], the virus has spread to every continent. The Covid-19 pandemic is more than a health crisis, it has created devastating social, economic, and political crises, leaving deep scars [5-8]. In Ukraine, the first confirmed case of Covid-19 was reported in March 2019. Unfortunately, Ukraine is now among the countries with the highest number of confirmed Covid19 cases [9].

The WHO has identified six strategic objectives (suppressing transmission, reducing exposure, countering misinformation and disinformation, protecting the most vulnerable, reducing mortality and morbidity, accelerating equitable access to new Covid-19 tools) for successful fighting against the Covid-19 pandemic to be implemented at the national, regional, and global levels $[10,11]$. Although the world has been in the pandemic mode for two years, regional differences in the prevalence, mortality rates, and immune responses are still unclear [12-14]. However, the rate of inpatient hospital admissions remains a key indicator of success in fighting against Covid-19 and the burden on health care [15-17]. Studying the indicators of health care at a local level might provide essential information for its improvement, adaptation and pandemic planning, development of effective anti-epidemic measures in the context of socio-demographic and geographic diversity of the population. This report was aimed to analyse the rates of Covid-19 hospital admissions at the Ivano-Frankivsk City Hospital, Ukraine.

\section{Materials and Methods}

Medical records of all patients admitted to the IvanoFrankivsk City Clinical Hospital No. 1 with a Covid-19 diagnosis (code U07.1) from April 2020 (first Covid-19 confirmed patient in Clinical Hospital No.1) to May 2021 
were analysed. A total of 2, 543 medical records were evaluated.

\section{Data Analysis}

Statistical analysis was performed in Microsoft Excel. The number of inpatient cases and deaths, types of hospital admissions, length of hospital stay, patients' age and gender were analysed. Quantitative data are presented as average values; qualitative data are presented as percentages. The analysis was carried out monthly and seasonally.

\section{Results and Discussion}

The analysis of hospital admissions during the study period showed two Covid-19 waves, which were observed in other healthcare centres as well; however, they shifted in time due to the spread of the pandemic and population migration [1821]. From April to September 2020, the monthly number of Covid-19 patients admitted to the hospital was stable; however, it increased in October, reaching the first peak in November 2020 (Fig. 1).

Then, in January 2021, the rate of Covid-19 admissions decreased, reaching the values for the period of JulySeptember 2020. However, in March 2021, the number of inpatient cases increased to 520 patients, that was 2.5fold higher than the planned hospital capacity ( 240 hospital beds in 2019). On the other hand, the average length of hospital stays for Covid-19 patients ranged from 12 to 14 days.

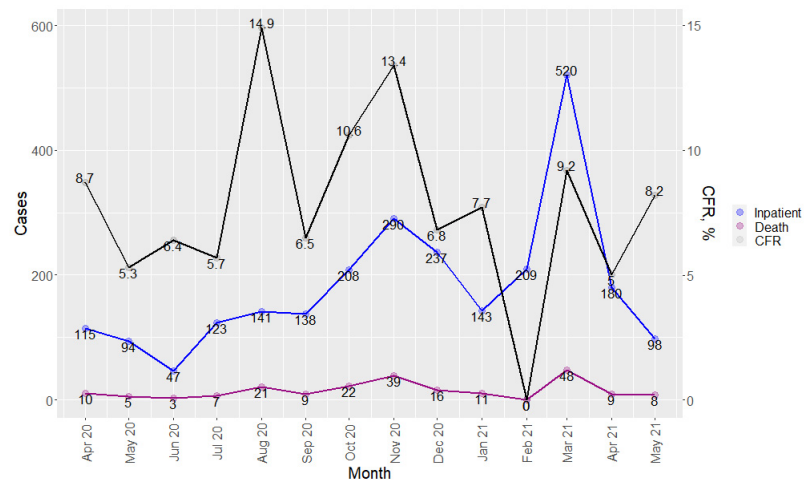

Figure 1. Hospital admission and mortality rates between April 2020 and May 2021. CFR - case fatality rate.

The case fatality rate changed in accordance with inpatient cases. There were observed two Covid-19 peaks, in August and November 2020. Since December 2020, this indicator decreased, but fluctuated within the range of 5.0$9.2 \%$. This stabilization might be due to the adaptation of healthcare system to the pandemic and better management of Covid-19 patients.

Sex-stratified analysis of cumulative inpatient cases showed slightly higher prevalence rates in women $(54.7 \%)$ then men (45.3\%). From April to May 2020, the rate of hospital admissions for females exceeded that for males twice $-63.2 \%$ vs. $36.8 \%$. However, several studies have indicated a possibility of gender predisposition to Covid19 , with men predisposed to being most severely affected and having the highest mortality rate [13, 22-24]. These differences might be caused by demographic, social and geographic aspects. Since June 2020, the rate of hospital admissions for males increased; however, between March and May 2021, the sex ratio shifted, accounting for $54.4 \%$ of women vs. $45.6 \%$ of men. In our opinion, this may be due to gender-specific health behaviour [25]. On the other hand, this trend was noticeable at the beginning of the pandemic, when the infection spread was slow, and its natural circulation and negative health effects were not fully established [26-28]. This hypothesis has been confirmed by the analysis of sex-disaggregated mortality data and is consistent with other studies [12, 29, 30]. Among 208 patients who died of Covid-19 during the study period, there were $61.9 \%$ of men and $38.1 \%$ of women. The male mortality rate was especially high $(80.0 \%)$ between April and May 2020 (Fig. 2). However, from March to May 2021, sex-disaggregated data for Covid-19-related deaths were as follows: $46.8 \%$ of men and $53.2 \%$ of women that was similar to those for hospital admissions.

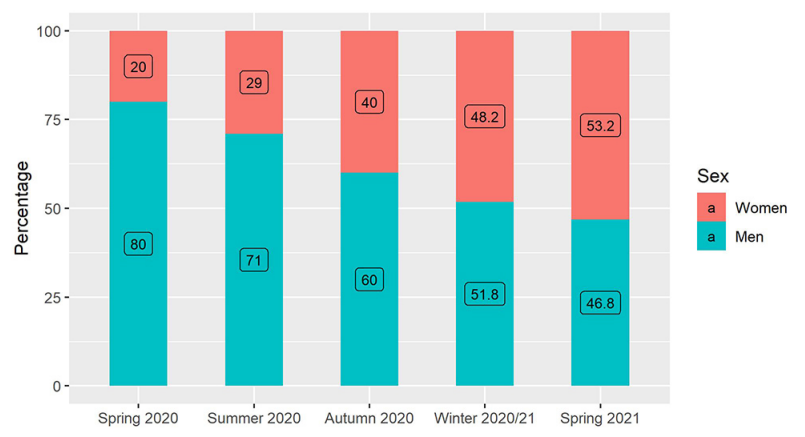

Figure 2. Sex-disaggregated Covid-19 mortality data (April 2020 - May 2021).

The average age of Covid-19 patients admitted to the hospital was $58.9 \pm 1.3$ years, ranging from $51.3 \pm 2.3$ (June 2020) to $62.1 \pm 0.8$ (November 2020) years (Fig. 3). It should be noted that the vast majority of Covid-19 deaths occurred among the elderly $(69.2 \pm 2.4$ years $)$. The analysis of age- and sex-disaggregated Covid-19 mortality data has showed that the average age at death from Covid-19 was $71.8 \pm 2.3$ years for women and $66.6 \pm 3.9$ years for men and confirmed that sex and age may be key factors leading to fatal outcomes in Covid-19 patients [31-34].

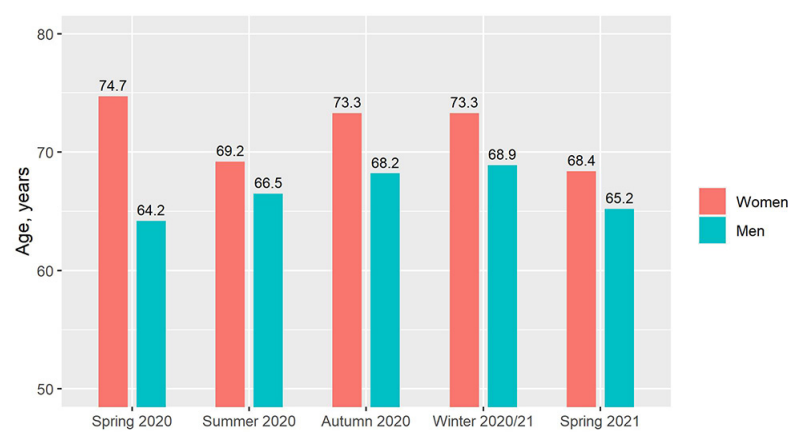

Figure 3. Age-disaggregated Covid-19 mortality data (April 2020 - May 2021). 
The ratio of Covid-19 hospital admission types was different over the study period. In spring 2020, the percentage of patients admitted to the hospital by ambulance, those referred by their GP and self-referred patients was similar (Fig. 4). However, between June 2020 and February 2021 , the rate of emergency admissions decreased to $15.7-23.3 \%$. The highest rate of self-referral admissions was observed from June to August 2020, with a gradual decrease $(13.2 \%)$ between March and May 2021. On the other hand, the number of Covid-19 patients admitted to the hospital by their GPs was stable and increased to $45.1 \%$ in spring 2021. This may indicate more effective management of patient flow, changes in their health behaviour in relation to preventive anti-epidemic measures.

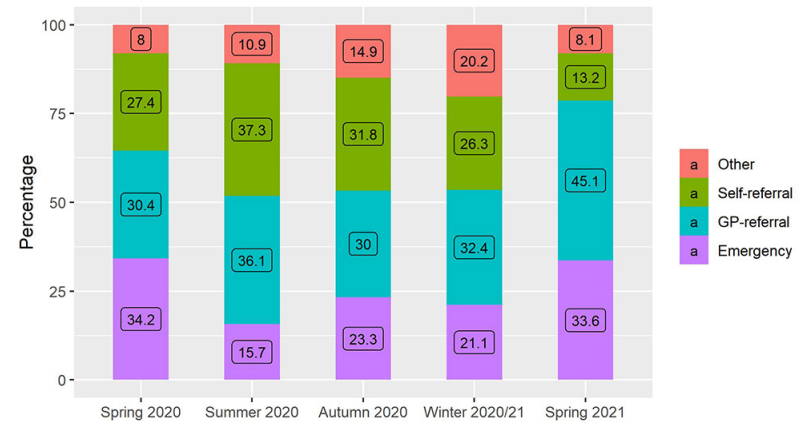

Figure 4. Structure of the types of Covid-19 hospital admissions.

\section{Limitations}

This observational study is limited to its objective and design; describes the rates of admission to one city hospital over the study period; the results of this study do not reflect the actual scale of the pandemic in Ukraine as they are limited to the regional level and cannot be applied to all the pandemic periods.

\section{Conclusions}

Within the limitations of the study, the trends in hospital admissions were similar to those highlighted in other studies. However, there were differences in time frames and socio-demographic characteristics which indicates the importance of local adaptation of healthcare system to the pandemic and the development of preventive anti-epidemic measures at the regional level, considering social and geographic aspects.

\section{Ethical Statement \& Informed Consent}

This study was approved by the administration of the IvanoFrankivsk City Clinical Hospital No. 1, Ivano-Frankivsk, Ukraine. The research was performed according to the Declaration of Helsinki; the Principles of Privacy and Confidentiality of Sensitive Medical Data were preserved. Patients' informed consents regarding using their deidentified medical records for research were obtained prospectively when they were admitted to the hospital.

\section{Conflict of Interest}

The authors declare that no conflicts exist.

\section{Financial Disclosure}

The authors declared no financial support.

\section{References}

[1] Rogers RG, Swift S. The world is upside down; how coronavirus changes the way we care for our patients. International Urogynecology Journal. 2020;31(5):853-854. Available from: https://doi.org/10.1007/s00192-020-04292-7

[2] Pollard CA, Morran MP, Nestor-Kalinoski AL. The COVID-19 pandemic: a global health crisis. Physiological Genomics. 2020;52(11):549-557. Available from: https://doi.org/10.1152/physiolgenomics.00089.2020

[3] Khan M, Khan H, Khan S, Nawaz M. Epidemiological and clinical characteristics of coronavirus disease (COVID-19) cases at a screening clinic during the early outbreak period: a single-centre study. Journal of Medical Microbiology. 2020;69(8):1114-1123. Available from: https://doi.org/10.1099/jmm.0.001231

[4] Awadasseid A, Wu Y, Tanaka Y, Zhang W. Initial success in the identification and management of the coronavirus disease 2019 (COVID19) indicates human-to-human transmission in Wuhan, China. International Journal of Biological Sciences. 2020;16(11):1846-1860. Available from: https://doi.org/10.7150/ijbs.45018

[5] Saha K, Torous J, Caine ED, De Choudhury M. Psychosocial effects of the COVID-19 pandemic: largescale quasi-experimental study on social media. Journal of Medical Internet Research. 2020;22(11):e22600. Available from: https://doi.org/10.2196/22600

[6] Matthes J, Koban K, Neureiter A, Stevic A. Longitudinal relationships among fear of COVID-19, smartphone online self-disclosure, happiness, and psychological well-being: survey study. Journal of Medical Internet Research. 2021;23(9):e28700. Available from: https://doi.org/10.2196/28700

[7] Graffigna G, Palamenghi L, Savarese M, Castellini G, Barello S. Effects of the COVID-19 emergency and national lockdown on Italian citizens' economic concerns, government trust, and health engagement: evidence from a two-wave panel study. The Milbank Quarterly. 2021;99(2):369-392. Available from: https://doi.org/10.1111/1468-0009.12506

[8] Mbunge E. Effects of COVID-19 in South African health system and society: an explanatory study. Diabetes \& Metabolic Syndrome: Clinical Research \& Reviews. 2020;14(6):1809-1814. Available from: https://doi.org/10.1016/j.dsx.2020.09.016 
[9] National Security and Defense Council of Ukraine. Coronavirus epidemic monitoring system [Internet]. 2021 [cited 2021 Nov 1]. Available from: https://COVID19.rnbo.gov.ua/

[10] United Nations Development Programme [Internet]. 2021 [cited 2021 Sep 15]. Available from: https://www.ua.undp.org/content/ukraine/en/home/aboutus/who-we-are.html

[11] World Health Organization. COVID-19 Strategic preparedness and response plan. Geneva: World Health Organization; 2021. Available from: https://www.swissphilanthropy.ch/wpcontent/uploads/2021/02/WHO-COVID_19-

Strategic-Preparedness-and-Response-Plan-2021.pdf

[12] Bienvenu LA, Noonan J, Wang X, Peter K. Higher mortality of COVID-19 in males: sex differences in immune response and cardiovascular comorbidities. Cardiovascular Research. 2020;116(14):2197-2206. Available from: https://doi.org/10.1093/cvr/cvaa284

[13] Papadopoulos V, Li L, Samplaski M. Why does COVID-19 kill more elderly men than women? Is there a role for testosterone? Andrology. 2020;9(1):65-72. Available from: https://doi.org/10.1111/andr.12868

[14] Ivanov A, Semenova E. Long-term monitoring of the development and extinction of $\operatorname{IgA}$ and $\operatorname{IgG}$ responses to SARS-CoV-2 infection. Journal of Medical Virology. 2021;93(10):5953-5960. Available from: https://doi.org/10.1002/jmv.27166

[15] Sapiano MRP, Dudeck MA, Soe M, Edwards JR, O'Leary EN, Wu $\mathrm{H}$, et al. Impact of coronavirus disease 2019 (COVID-19) on US Hospitals and Patients, April-July 2020. Infection Control \& Hospital Epidemiology. 2021;1-8. Available from: https://doi.org/10.1017/ice.2021.69

[16] Kapsner LA, Kampf MO, Seuchter SA, Gruendner J, Gulden $\mathrm{C}$, Mate $\mathrm{S}$, et al. Reduced rate of inpatient hospital admissions in 18 German university hospitals during the COVID-19 lockdown. Frontiers in Public Health. 2021;8:594117. Available from: https://doi.org/10.3389/fpubh.2020.594117

[17] Helgeland J, Telle KE, Grøsland M, Huseby BM, Håberg S, Lindman ASE. Admissions to Norwegian Hospitals during the COVID-19 Pandemic. Scandinavian Journal of Public Health. 2021;49(7):681-688. Available from: https://doi.org/10.1177/14034948211000813

[18] Amengual O, Atsumi T. COVID-19 pandemic in Japan. Rheumatology International. 2020;41(1):1-5. Available from: https://doi.org/10.1007/s00296-02004744-9

[19] Sarkar A, Chakrabarti AK, Dutta S. Covid19 Infection in India: a comparative analysis of the second wave with the first wave. Pathogens. 2021;10(9):1222. Available from: https://doi.org/10.3390/pathogens10091222
[20] Saito S, Asai Y, Matsunaga N, Hayakawa K, Terada M, Ohtsu H, et al. First and second COVID-19 waves in Japan: a comparison of disease severity and characteristics. Journal of Infection. 2021;82(4):84-123. Available from: https://doi.org/10.1016/j.jinf.2020.10.033

[21] Ayala A, Villalobos Dintrans P, Elorrieta F, Castillo C, Vargas C, Maddaleno M. Identification of COVID19 waves: considerations for research and policy. International Journal of Environmental Research and Public Health. 2021;18(21):11058. Available from: https://doi.org/10.3390/ijerph182111058

[22] Lanser L, Burkert FR, Thommes L, Egger A, Hoermann G, Kaser S, et al. Testosterone deficiency is a risk factor for severe COVID-19. Frontiers in Endocrinology. 2021;12:694083. Available from: https://doi.org/10.3389/fendo.2021.694083

[23] Giagulli VA, Guastamacchia E, Magrone T, Jirillo E, Lisco G, De Pergola G, et al. Worse progression of COVID-19 in men: is testosterone a key factor? Andrology. 2020;9(1):53-64. Available from: https://doi.org/10.1111/andr.12836

[24] Meyerowitz-Katz G, Merone L. A systematic review and meta-analysis of published research data on COVID-19 infection fatality rates. International Journal of Infectious Diseases. 2020;101:138-148. Available from: https://doi.org/10.1016/j.ijid.2020.09.1464

[25] O’Neil A, Scovelle AJ, Milner AJ, Kavanagh A. Gender/sex as a social determinant of cardiovascular risk. Circulation. 2018;137(8):854-864. Available from: https://doi.org/10.1161/CIRCULATIONAHA.117. 028595

[26] Profeta P. Gender equality and public policy during COVID-19. CESifo Economic Studies. 2020;66(4):365-375. Available from: https://doi.org/10.1093/cesifo/ifaa018

[27] Wenham C, Smith J, Morgan R. Covid-19 is an opportunity for gender equality within the workplace and at home. BMJ. 2020;369:m1546. Available from: https://doi.org/10.1136/bmj.m1546

[28] King T, Hewitt B, Crammond B, Sutherland G, Maheen $\mathrm{H}$, Kavanagh A. Reordering gender systems: can COVID-19 lead to improved gender equality and health? The Lancet. 2020;396(10244):80-81. Available from: https://doi.org/10.1016/S01406736(20)31418-5

[29] Levin AT, Hanage WP, Owusu-Boaitey N, Cochran KB, Walsh SP, Meyerowitz-Katz G. Assessing the age specificity of infection fatality rates for COVID-19: systematic review, meta-analysis, and public policy implications. European Journal of Epidemiology. 2020;35(12):1123-1138. Available from: https://doi.org/10.1007/s10654-020-00698-1 
[30] Salah HM, Mehta JL. Hypothesis: Sex-related differences in ACE2 activity may contribute to higher mortality in men versus women with COVID19. Journal of Cardiovascular Pharmacology and Therapeutics. 2020;26(2):114-118. Available from: https://doi.org/10.1177/1074248420967792

[31] Li X, Xu S, Yu M, Wang K, Tao Y, Zhou Y, et al. Risk factors for severity and mortality in adult COVID-19 inpatients in Wuhan. Journal of Allergy and Clinical Immunology. 2020;146(1):110-118. Available from: https://doi.org/10.1016/j.jaci.2020.04.006

[32] Esfahanian F, SeyedAlinaghi S, Janfaza N, Tantuoyir MM. Predictors of hospital mortality among patients with COVID-19 in Tehran, Iran. SAGE Open Medicine. 2021;9:205031212110515. Available from: https://doi.org/10.1177/20503121211051573

[33] Dehingia N, Raj A. Sex differences in COVID-19 case fatality: do we know enough? The Lancet Global Health. 2021;9(1):e14-e15. Available from: https://doi.org/10.1016/S2214-109X(20)30464-2

[34] Undurraga EA, Chowell G, Mizumoto K. COVID-19 case fatality risk by age and gender in a high testing setting in Latin America: Chile, March-August 2020. Infectious Diseases of Poverty. 2021;10(1):11. Available from: https://doi.org/10.1186/s40249-02000785-1

Received: $2021-10-12$

Revision Requested: 2021-10-31

Revision Received: 2021-11-11

Accepted: 2021-11-16 